Tropical Journal of Pharmaceutical Research February 2014; 13 (2): 229-234

ISSN: $1596-5996$ (print); 1596-9827 (electronic)

(c) Pharmacotherapy Group, Faculty of Pharmacy, University of Benin, Benin City, 300001 Nigeria.

All rights reserved.

Available online at http://www.tjpr.org

Original Research Article

http://dx.doi.org/10.4314/tjpr.v13i2.10

\title{
Polysaccharides from Portulaca oleracea L Improve Exercise Endurance and Decrease Oxidative Stress in Forced Swimming Mice
}

\author{
Chen Xiang ${ }^{1^{*}}$, Lan Zhang ${ }^{2}$, Zheng Xiaowei ${ }^{3}$ and Lou Xiaojuan ${ }^{4}$ \\ ${ }^{1}$ Physical Education College, Wenzhou University, Wenzhou 325035, ${ }^{2}$ Department of Physical Education, Zhejiang Yuexiu \\ University of Foreign Languages, Shaoxing, 312000, ${ }^{3}$ Department of Physical Education and Military Training, Zhejiang \\ University of Technology, Hangzhou, 310014, ${ }^{4}$ Physical Education College, Donghua University, Shanghai 201620, PR China.
}

*For correspondence: Email: tyxycx@sina.cn, tyxycx@gmail.com; Tel: +86 13868551014; Fax: +86 057786680835

Received: 26 December 2012

Revised accepted: 5 January 2014

\begin{abstract}
Purpose: To explore the effects of polysaccharides from Portulaca oleracea $L$. (POP) on exercise endurance and oxidative stress in forced-swimming mice.

Methods: Forty-eight mice were divided into four groups of twelve animals each. All treatments were administered orally and daily for 28 days. Group $A$ received isotonic saline solution $(50 \mathrm{ml} / \mathrm{kg}$ bodyweight) as control group; B, C and D groups received 100, 200 and $400 \mathrm{mg} / \mathrm{kg}$ body wt. of POP as treatment groups, respectively. After the final treatment with $P O P$, the mice were subjected to swimming to exhaustion and the exhaustive swimming time, blood lactic acid (BLA), blood glucose, malondialdehyde (MDA), superoxide dismutase (SOD), glutathione peroxidase (GPX) and catalase (CAT) were measured.

Results: The exhaustive swimming time of the POP-treated groups $(967.3 \pm 79.2,1234.8 \pm 97.6$ and $1314.3 \pm 107.3 \mathrm{~s})$ was significantly longer than that of the control group (513.6 $\pm 41.2 s)(p<0.05)$. After the exhaustive swimming exercise, BLA levels of the POP-treated groups $(8.63 \pm 0.91,8.04 \pm 0.86$ and $7.51 \pm 0.78 \mathrm{mmol} / \mathrm{L})$ were significantly lower than that of the control group $(11.39 \pm 1.17 \mathrm{mmol} / \mathrm{L})(p<$ $0.05)$. MDA levels of the POP-treated groups (2.69 $\pm 0.21,2.41 \pm 0.17$ and $2.37 \pm 0.23 \mathrm{U} / \mathrm{mg}$.pro) were significantly lower than that of the control group (3.21 $\pm 0.29 U / \mathrm{mg} . p r o)(p<0.05)$. On the other hand, blood glucose levels of the POP-treated groups $(5.47 \pm 0.48,5.74 \pm 0.57$ and $6.04 \pm 0.51 \mathrm{mmol} / \mathrm{L})$ were significantly higher than that of the control group $(4.89 \pm 0.32 \mathrm{mmol} / \mathrm{L})(p<0.05)$. SOD levels of the POP-treated groups (124.36 $\pm 14.87,136.39 \pm 13.48$ and $145.87 \pm 17.39 \mathrm{U} / \mathrm{mg}$.pro) were significantly higher than that of the control group (108.41 $\pm 11.63 \mathrm{U} / \mathrm{mg} . \mathrm{pro})(p<0.05)$. GPx levels of the POPtreated groups (68.24 $\pm 4.68,71.33 \pm 5.29$ and $72.64 \pm 5.99$ U/mg.pro) were significantly higher than that of the control group $(53.17 \pm 5.24 \mathrm{U} / \mathrm{mg}$.pro) $(p<0.05)$. CAT levels of the POP-treated groups $(23.57 \pm 1.71,24.28 \pm 2.14$ and $26.72 \pm 2.21 \mathrm{U} / \mathrm{mg}$.pro) were significantly higher than that of the control group (19.48 $\pm 2.03 \mathrm{U} / \mathrm{mg}$.pro) $(p<0.05)$.

Conclusion: This study provides compelling evidence that POP can improve exercise endurance and decrease oxidative stress in forced swimming mice.
\end{abstract}

Keywords: Polysaccharides, Portulaca oleracea L., Oxidative stress, Swimming, Exercise endurance.

Tropical Journal of Pharmaceutical Research is indexed by Science Citation Index (SciSearch), Scopus, International Pharmaceutical Abstract, Chemical Abstracts, Embase, Index Copernicus, EBSCO, African Index Medicus, JournalSeek, Journal Citation Reports/Science Edition, Directory of Open Access Journals (DOAJ), African Journal Online, Bioline International, Open-J-Gate and Pharmacy Abstracts 


\section{INTRODUCTION}

Portulaca oleracea L. (Family Portulacaceae) is listed by the World Health Organization as one of the most used medicinal plants and has been termed, "Global Panacea" [1]. It is a succulent, prostrate or erect annual, with green or purple stems swollen at the nodes, up to $50 \mathrm{~cm}$ long. It has a cosmopolitan distribution in China, Africa, India, Australia, Middle East, Europe and United States and has a long history of use as a medicinal and edible plant [2]. In traditional Chinese medicine, Portulaca oleracea $L$. is utilized as an antipyretic, anti-scorbutic, antiseptic, antispasmodic, diuretic, antihelmetic and for treatment of urinary disorders. The aerial parts of the plant are used medicinally for reducing pain and swelling [3]. It has been reported that Portulaca oleracea $L$. has a wide range of pharmacological actions including antibacterial, analgesic, antidiabetic, antiinflammatory, skeletal muscle-relaxant, woundhealing and antiulcer activities [4].

Portulaca oleracea L. contains several biologically-active compounds including organic acids, alkaloids, coumarins, flavonoids, cardiac glycosides and polysaccharides etc. [5].

The polysaccharides are an important class of biological polymers. Recently, the bio-activities of polysaccharides from plants and fungi have attracted more and more attention in biochemistry and medicine [6-9].

In the last few decades, several studies have shown that polysaccharides from Portulaca oleracea L. (POP) exhibit strong antioxidant, anticancer, anti-microbial, anti-diabetic and antiinflammatory properties [10]. So far, there has been little reported work on the effects of POP on exercise endurance and oxidative stress induced by exercise. Therefore, in this study, the objective was to investigate the effects of POP on exercise endurance and oxidative stress in forced swimming mice.

\section{EXPERIMENTAL}

\section{Collection and identification of plant material}

The fresh Portulaca oleracea $L$. (whole herb) was collected from the suburb of Wenzhou city in June 2010 and identified in the Hangzhou Institute of Botany, Hangzhou, China by a senior plant taxonomist, Professor Li MY. An authentic voucher specimen (no. WU-MC 0187) was deposited in the Herbarium of Wenzhou University (Wenzhou, China). The collected plant was washed with distilled water, and air-dried. The dried Portulaca oleracea $L$. was ground into a coarse powder with the help of a suitable grinder. The powder was stored in an airtight container and kept in a cool, dark and dry place until used

\section{Preparation of polysaccharides from Portulaca oleracea $L$.}

The polysaccharides from Portulaca oleracea $L$. (POP) were prepared according to a previously published method [4]. In brief, the powder of Portulaca oleracea $L$. was extracted in a soxhlet apparatus with a mixture of chloroform-methanol $\left(2: 1,75^{\circ} \mathrm{C}\right)$, and pre-treated with $80 \%$ ether twice to remove some coloured materials, oligosaccharides, and some small molecule materials. The organic solvent portion was volatilized and pretreated dry powder was obtained. The pretreated dry powder $(500 \mathrm{~g})$ was extracted twice with boiling water $(4000 \mathrm{~mL})$ for 3 $\mathrm{h}$. The aqueous extracts were combined and centrifuged $(2000 \mathrm{~g}, 20 \mathrm{~min})$, then the supernatant was separated from insoluble residue with nylon cloth (pore diameter: $38 \mathrm{um}$ ). The aqueous extracts were then defatted by the method of Sevag [11], precipitated by the addition of ethanol to a final concentration of $80 \%(\mathrm{v} / \mathrm{v})$. The precipitates were collected by centrifugation $(2000 \mathrm{~g}, 20 \mathrm{~min})$. It was then solubilized in deionized water and lyophilized to get POP.

\section{Assay kits and reagents}

Glucose reagent kits were purchased from Rongsheng Biotech Co. (Shanghai, China). Blood lactic acid (BLA), superoxide dismutase (SOD), glutathione peroxidase (GPx) and catalase (CAT) and malondialdehyde (MDA) reagent kits were purchased from Jianchen Biological Engineering Institute (Nanjing, China). All other chemicals were of analytical grade and were purchased from Zhejiang Chemical Reagent Co., Ltd (Hang zhou, China).

\section{Animals and grouping}

Healthy male Kunming mice weighing 18 to $22 \mathrm{~g}$ were used throughout the experiment. The animals were purchased from the Animal Center of the Wenzhou Medical College (Wenzhou, China). The approval of this experiment was obtained from the Ethics Committee of Wenzhou University (no. WZU 2010-27), and the tests carried out according to the "Principles of Laboratory Animal Care" (World Health Organization Chronicle, 1985). The animal breeding room was maintained under a constant 12-h light: 12-h dark cycle with a temperature of $22 \pm 2{ }^{\circ} \mathrm{C}$ and relative humidity of $55 \pm 5 \%$ throughout the experimental period. They were 
given free access to standard feed pellets and water.

The mice were trained to accustom themselves to swimming twice (5 min per time) in the first week. During the period, the mice which could not learn to swim were screened out. Forty-eight mice were divided into four groups of twelve animals each. All were administered orally and daily for 28 days. A group received isotonic saline solution (50 ml/kg bodyweight) as control group; B, C and D groups received 100, 200 and $400 \mathrm{mg} / \mathrm{kg}$ body wt. of POP as treatment groups, respectively.

\section{Swimming exercise test}

The swimming exercise test was employed in this study to evaluate the effects of POP on exercise endurance. After the final treatment with POP, the mice were taken out for the forced swimming exercise. The procedure used was described previously with some modifications [12]. Briefly, the mice were dropped individually into an acrylic plastic pool $(50 \mathrm{~cm} \times 50 \mathrm{~cm} \times 40$ $\mathrm{cm}$ ) filled with fresh water maintained at $25 \pm 2$ ${ }^{\circ} \mathrm{C}$, approximately $30 \mathrm{~cm}$ deep so that mice could not support themselves by touching the bottom with their tails. A lead block ( $5 \%$ of body weight) was loaded on the tail root of the mice. The exhaustive swimming time was used as the index of the exercise endurance. The mice were assessed to be exhausted when they failed to rise to the surface of water to breathe within a 10-s period [13].

\section{Preparation of blood and tissue sample}

Immediately after exhaustive swimming exercise, all the mice were anesthetized with ether and the blood samples were collected in tubes by heart puncture for the determination of glucose and BLA. In addition, immediately after the blood had been collected, the liver were carefully removed, rinsed in ice-cold normal saline, blotted dry and stored at $-80{ }^{\circ} \mathrm{C}$ for MDA and anti-oxidant enzymes (SOD, GPx and CAT) analysis. Glucose, BLA, MDA and anti-oxidant enzymes were analysed according to the recommended procedures provided by the commercial reagent kits.

\section{Statistical analysis}

All the data were subjected to analysis of variance and tested for significant differences by Duncan's multiple range tests using SAS software version 9.2 (SAS Institute, Cary, NC). $P$ values $<0.05$ were considered significant.

\section{RESULTS}

Fig 1 shows the effect of POP on exercise endurance of mice. The exhaustive swimming time of the A, B, C and D group were 513.6 \pm $41.2,967.3 \pm 79.2,1234.8 \pm 97.6,1314.3 \pm$ $107.3 \mathrm{~s}$, respectively. Thus, the exhaustive swimming time of the POP treatment $(B, C$ and D) groups were significantly longer than that of the control $(A)$ group $(p<0.05)$.

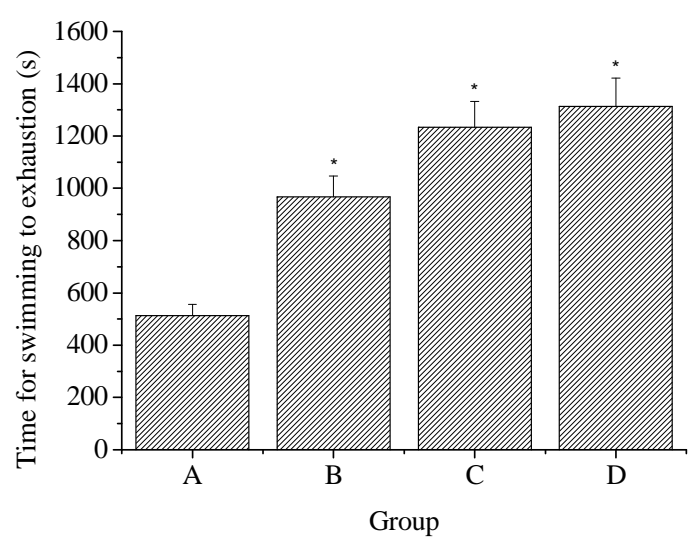

Fig 1: Effect of POP on exercise endurance of mice. Data are mean $\pm \mathrm{SD} ;{ }^{*} p<0.05$ compared with control (A) group.

Fig 2 shows the effect of POP on BLA of mice. After exhaustive swimming exercise, the BLA contents of the $A, B, C$ and $D$ group were $11.39 \pm$ $1.17,8.63 \pm 0.91,8.04 \pm 0.86,7.51 \pm 0.78$ $\mathrm{mmol} / \mathrm{L}$, respectively. Thus, the BLA contents of the POP treatment ( $B, C$ and $D)$ groups were significantly lower than that of the control $(A)$ group $(p<0.05)$.

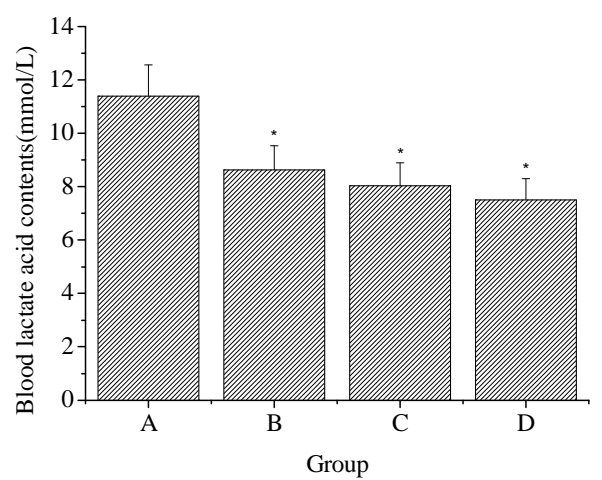

Fig 2: Effects of POP on blood lactic acid of mice. Data are mean $\pm \mathrm{SD} ;{ }^{*} p<0.05$ compared with control (A) group

Fig 3 show the effects of POP on blood glucose of mice. After exhaustive swimming exercise, the blood glucose contents of the $A, B, C$ and $D$ group were $4.89 \pm 0.32,5.47 \pm 0.48,5.74 \pm 0.57$, $6.04 \pm 0.51 \mathrm{mmol} / \mathrm{L}$, respectively. Thus, blood glucose contents of the POP treatment $(B, C$ and 
D) groups were significantly higher than that of the control $(\mathrm{A})$ group $(p<0.05)$.

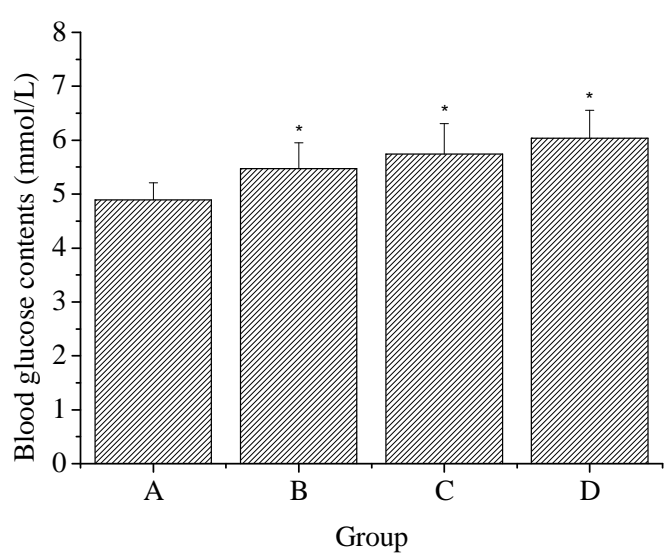

Fig 3: Effect of POP on blood glucose of mice. Data are mean $\pm S D ;{ }^{*} p<0.05$ compared with control $(A)$ group.

Fig 4 shows the effects of POP on MDA of mice. After exhaustive swimming exercise, the MDA contents of the A, B, C and D group were $3.21 \pm$ $0.29,2.69 \pm 0.21,2.41 \pm 0.17,2.37 \pm 0.23$ $\mathrm{U} / \mathrm{mg}$.pro, respectively. Thus, the MDA contents of the POP treatment $(B, C$ and $D)$ groups were significantly lower than that of the control $(A)$ group $(p<0.05)$.

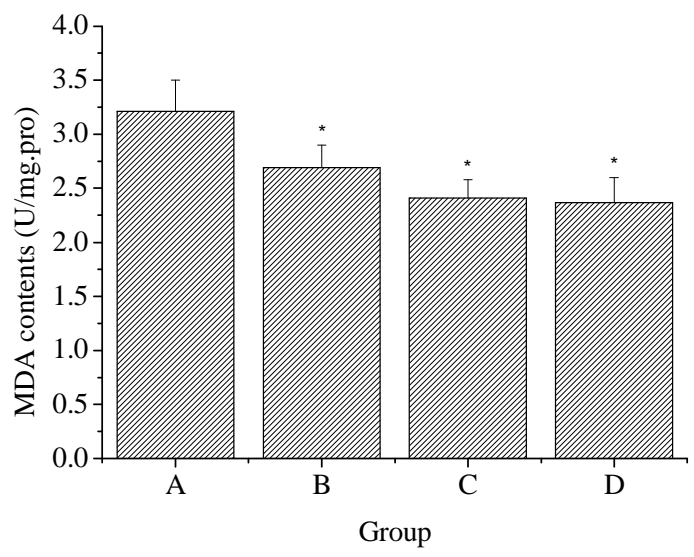

Fig 4: Effect of POP on MDA in liver of mice. Data are mean $\pm S D ;{ }^{*} p<0.05$ compared with control $(A)$ group

\section{Effect of POP on antioxidant enzymes in liver of mice}

Table 1 showed the effect of POP on antioxidant enzymes of mice. After exhaustive swimming exercise, the SOD, GPx, and CAT contents of the POP treatment $(B, C$ and $D)$ groups were significantly higher than that of the control $(A)$ group $(p<0.05)$.
Table 1: Effect of POP on antioxidant enzymes of mice liver

\begin{tabular}{lcll}
\hline Group & SOD(U/mg.pro) & $\begin{array}{l}\text { GPx } \\
\text { (U/mg.pro) }\end{array}$ & CAT(U/mg.pro) \\
\hline A & $108.41 \pm 11.63$ & $53.17 \pm 5.24$ & $19.48 \pm 2.03$ \\
B & $124.36 \pm 14.87^{*}$ & $68.24 \pm 4.68^{*}$ & $23.57 \pm 1.71^{*}$ \\
C & $136.39 \pm 13.48^{*}$ & $71.33 \pm 5.29^{*}$ & $24.28 \pm 2.14^{*}$ \\
D & $145.87 \pm 17.39^{*}$ & $72.64 \pm 5.99^{*}$ & $26.72 \pm 2.21^{*}$ \\
\hline Data are mean $\pm S D ;$ & $p<0.05$ compared with control (A) \\
group. &
\end{tabular}

\section{DISCUSSION}

In the present study, in vivo swimming exercise test was chosen over other exercise tests, since it allows for reliable and reproducible evaluation of exercise endurance in mice [14]. To standardize the workload and reduce the swimming time, weights at specific body weight percentages were added to the chest or tail of the animal. The exhaustive swimming time was used as the index of the exercise endurance. In the current study, the data show that the exhaustive swimming time of the POP treatment groups were significantly longer than that of the control group. These results indicated that POP could improve exercise endurance.

The swimming exercise is known to induce some blood biochemical changes. Generally, it is interpreted that a decrease in blood glucose shows a consumption of energy and that the increase of blood lactate acid (BLA) presents a fatigued condition during prolonged exercise [13]. $B L A$ is the glycolytic product of glucose under anaerobic conditions. During exercise, organs such as liver and heart, and tissues such as skeletal muscle, help to remove lactic acid from the blood, but intense exercise can increase lactate production [15]. In the current study, the data show that BLA contents of the POP treatment groups were significantly lower than that of the control group. These results indicate that POP could effectively attenuate the increase of BLA and it is possible that the improvement of physiological function or metabolic control of lactate production and/or removal may have contributed to the enhanced exercise endurance. Hypoglycemia can suppress the active functioning of the brain during exercise, and this often leads to the inability of continuing exercise. On the other hand, homeostasis of blood glucose plays an important role in prolonging endurance exercise [16]. It is known that endurance capacity is markedly decreased by the inhibition of gluconeogenesis, because gluconeogenesis plays a major role in glucose homeostasis during endurance exercise [17]. In the current study, the data show that blood glucose contents of the POP treatment groups were significantly higher than that of the control group. These results 
indicate that the POP improvement of exercise endurance must be related to the activation of energy metabolism.

Growing evidence has shown that that exercise increases oxygen utilization and causes formation of free radicals and reactive oxygen species (ROS). Moreover, strenuous aerobic exercise is associated with oxidative stress [18]. Oxidative stress may progress to oxidative damage involving cellular proteins (contractile, structural, and enzymatic), lipids, DNA, and other molecules in ways that might lead to abnormal cellular function [19]. Malondialdehyde (MDA) has been the most widely used parameter for evaluating oxidative damage to lipids, although it is known that oxidative damage to amino acids, proteins and DNA also causes release of MDA [20]. In the current study, the data showed that the MDA contents of the POP treatment groups were significantly lower than that of the control group. These results indicated that POP could reduce lipid per-oxidation and prevent exerciseinduced oxidative damage.

Antioxidant enzymes, which provide the primary defense against ROS generated during exercise, may be activated selectively during an acute bout of strenuous exercise depending on the oxidative stress imposed on the specific tissues as well as the intrinsic antioxidant defense capacity [21,22]. The major antioxidant enzymes are SOD, GPX and CAT. SOD catalyzes the dismutation of superoxide into oxygen and hydrogen peroxide. GPx catalyzes the reduction of hydroperoxides at the expense of reduced glutathione. CAT catalyzes the decomposition of hydrogen peroxide to water, sharing this function with GPx [23]. In the current study, the data show that the SOD, GPx, and CAT contents of the POP treatment groups were significantly higher than that of the control group. These results indicated that POP was able to up-regulate antioxidant enzyme activities to protect against oxidative stress induced by acute exercise

\section{CONCLUSION}

The results show that POP can extend the exhaustive swimming time of mice, as well as decrease BLA levels, while increasing blood glucose. Furthermore, POP elevates the levels of antioxidant enzymes (SOD, GPx and CAT) but decreases MDA levels in liver. This study provide compelling evidences that POP could improve exercise endurance and decrease oxidative stress, but the data are only in reference to mice. Future work using other models including humans of different sporting backgrounds is needed to extend these findings.

\section{ACKNOWLEDGEMENT}

This work was supported by the Natural Sciences Foundation of Shanghai City, China.

\section{REFERENCES}

1. Lim YY, Quah EPL. Antioxidant properties of different cultivars of Portulaca oleracea. Food Chem 2007; 103: $734-740$

2. Chan K, Islam MW, Kamil M, Radhakrishnan R, Zakaria MN, Habibullah $M$, Attas $A$. The analgesic and antiinflammatory effects of Portulaca oleracea $L$. subp. sativa (Haw.) Celak. J Ethnopharm 2000; 73: 445451.

3. Karimi G., Khoei A, Omidi A, Kalantari M, Babaei J, Taghiabadi E, Razavi BM. Protective effect of aqueous and ethanolic extracts of Portulaca oleracea against cisplatin induced nephrotoxicity. Iran J Basic Med Sci 2010; 13: 31-35

4. Li FL, Li QW, Gao DW, Peng Y, Feng CN. Preparation and antidiabetic activity of polysaccharide from Portulaca oleracea L. Afr J Biotech 2009; 8: 569-573.

5. YouGuo C, ZongJi S, XiaoPing C. Int J Biol Macromol. Evaluation of free radicals scavenging and immunitymodulatory activities of Purslane polysaccharides. Int J Biol Macromol 2009; 45:448-452.

6. Shi Y, Cai D, Wang X, Liu X. Immunomodulatory Effect of Ganoderma Lucidum Polysaccharides (GLP) on Long-Term Heavy-Load Exercising Mice. Int J Vitam Nutr Res 2012; 82: 383-390.

7. Safonova EA, Razina TG, Zueva EP, Lopatina $K A$, Efimova LA, Gur'ev AM, Rybalkina Olu, Khotimchenko luS. Prospects for the use of plant polysaccharides in complex treatment of malignant tumors. Eksp Klin Farmakol 2012; 75: 42-47.

8. Costa LS, Fidelis GP, Cordeiro SL, Oliveira RM, Sabry DA, Câmara RB, Nobre LT, Costa MS, Almeida-Lima J, Farias EH, Leite EL, Rocha HA. Biological activities of sulfated polysaccharides from tropical seaweeds. Biomed Pharmacother 2010; 64: 21-28.

9. Montoya S, Sanchez OJ, Levin L. Polysaccharide production by submerged and solid-state cultures from several medicinal higher Basidiomycetes. Int $J$ Med Mushrooms 2013; 15: 71-79.

10. Dong CX, Hayashi K, Lee JB, Hayashi $T$. Characterization of structures and antiviral effects of polysaccharides from Portulaca oleracea L. Chem Pharm Bull (Tokyo) 2010; 58: 507-510.

11. Sevag MG. Eine neue physikalische Enteiweißungsmethode zur Darstellung biologisch wirksamer Substanzen. Biochem Z 1934; 273: 419429.

12. Misra DS, Maiti $R$, Ghosh D. Protection of swimminginduced oxidative stress in some vital organs by the treatment of composite extract of Withania somnifera, Ocimum sanctum and Zingiber officinalis in malerat. Afr J Tradit Complement Altern Med 2009; 6: 534543.

13. Jung KA, Han D, Kwon EK, Lee CH, Kim YE. Antifatigue effect of Rubus coreanus Miquel extract in mice. $J$ Med Food 2007; 10: 689-693.

14. You Y, Kim K, Yoon HG, Lee KW, Lee J, Chun J, Shin $D H$, Park J, Jun W. Chronic effect of ferulic acid from Pseudosasa japonica leaves on enhancing exercise activity in mice. Phytother Res 2010; 24: 1508-1513.

15. Bonen A. Lactate transporters (MCT proteins) in heart and skeletal muscles. Med. Med Sci Sports Exe 2000; 2232: 778-789.

16. Wang JJ, Shieh MJ, Kuo SL, Lee CL, Pan TM. Effect of red mold rice on antifatigue and exercise-related changes in lipid peroxidation in endurance exercise. Appl Microbiol Biotechnol 2006; 70: 247-253. 
17. Oh TW, Oh TW, Ohta F. Dose-dependent effect of capsaicin on endurance capacity in rats. $\mathrm{Br} \mathrm{J}$ Nutr 2003; 90: 515-520.

18. Minato K, Miyake Y, Fukumoto S, Yamamoto K, Kato $Y$, Shimomura $Y$, Osawa T. Lemon flavonoid, eriocitrin, suppresses exerciseinduced oxidative damage in rat liver. Life Sci 2003; 72: 1609-1616.

19. Powers SK, Jackson MJ. Exercise-induced oxidative stress: cellular mechanisms and impact on muscle force production. Physiol Rev 2008; 88: 1243-1276.

20. Sun L, Shen W, Liu Z, Guan S, Liu J, Ding S. Endurance exercise causes mitochondrial and oxidative stress in rat liver: effects of a combination of mitochondrial targeting nutrients. Life Sci 2010; 86: 39-44.
21. Sen CK, Atalay M, Agren J, Laaksonen DE, Roy S, Hänninen $O$. Fish oil and vitamin E supplementation in oxidative stress at rest and after physical exercise. J App Physiol 1997; 83: 189-195.

22. Ide $T$, Tsutsui $H$, Hayashidani $S$, Kang $D$, Suematsu $N$, Nakamura K, Utsumi $H$, Hamasaki N, Takeshita A. Mitochondrial DNA damage and dysfunction associated with oxidative stress in failing hearts after myocardial infarction. Circ Res 2001; 88: 529-535.

23. Ryter SW, Kim HP, Hoetzel A, Park JW, Nakahira K, Wang $X$, Choi AM. Mechanisms of cell death in oxidative stress. Antioxid Redox Signal 2007; 9: 4989. 